\title{
CIMENTAÇÃO DE BANDA ORTODÔNTICA COM NOVO CIMENTO DE IONÔMERO DE VIDRO MODIFICADO POR RESINA
}

\author{
ORTHODONTIC BAND CIMENTATION WITH NEW RESIN-MODIFIED GLASS IONOMER CEMENT
}

\author{
Fábio Lourenço Romano * \\ Lourenço Correr Sobrinho ** \\ Américo Bortolazzo Correr *** \\ Edvaldo Luiz Ramalli **** \\ Maria Beatriz Borges de Araújo Magnani ****** \\ Darcy Flávio Nouer ********
}

\section{RESUMO}

O objetivo deste trabalho é mostrar a aplicação na Ortodontia do cimento de ionômero de vidro modificado por resina Fuji Ortho Band. A seqüência clínica de cimentação da banda com esse material foi detalhada, sendo ilustrado cada passo do procedimento, como: seleção e adaptação da banda, profilaxia e manipulação do cimento Fuji Ortho Band, de acordo com as recomendaçôes do fabricante e cimentação propriamente dita.

DESCRITORES: Cimentos de ionômeros de vidro - Ortodontia.

\section{ABSTRACT}

The aim of this study is to show the orthodontic application of the resin-modified glass ionomer cement Fuji Ortho Band. The clinical sequence of band cementation with this material was explained, being with each step of procedure illustrated, as: band selection and adaptation, prophylaxis and Fuji Ortho Band cement manipulation according to the manufacturers' instructions and properly cementation.

DESCRIPTORS: Glass ionomer cements - Orthodontics.

* Doutorando em Ortodontia - Faculdade de Odontologia de Piracicaba - FOP - Universidade Estadual de Campinas - UNICAMP; Professor de Ortodontia da Universidade Federal de Alfenas - UNIFAL

** Professor Titular da área de Materiais Dentários - Faculdade de Odontologia de Piracicaba - FOP - Universidade Estadual de Campinas - UNICAMP

*** Doutorando em Ortodontia - Faculdade de Odontologia de Piracicaba - FOP - Universidade Estadual de Campinas - UNICAMP

**** Doutor em Ortodontia - Faculdade de Odontologia de Piracicaba - FOP - Universidade Estadual de Campinas - UNICAMP; Professor de Ortodontia da Universidade de Ribeirão Preto - UNAERP

***** Professora Doutora da área de Ortodontia - Faculdade de Odontologia de Piracicaba - FOP - Universidade Estadual de Campinas - UNICAMP

****** Professor Titular de Ortodontia da Faculdade de Odontologia de Piracicaba - FOP - Universidade Estadual de Campinas - UNICAMP 
Romano FL, Correr Sobrinho L, Correr AB, Ramalli EL, Magnani MBBA, Nouer DF. Cimentação de banda ortodôntica com novo cimento de ionômero de vidro modificado por resina. Revista de Odontologia da Universidade Cidade de São Paulo 2008 jan-abr; 20(1):87-92

\section{INTRODUÇÃO}

Com a evolução dos materiais utilizados para fixação de acessórios ortodônticos ao esmalte, o procedimento de bandagem tem sido pouco utilizado. Inúmeras são as vantagens da colagem direta de bráquetes ao esmalte dentário em relação à bandagem, entre elas, podemos citar, menor tempo de cadeira, menor desconforto para o paciente, maior rapidez na montagem do aparelho, estética superior, facilidade de higienização com conseqüente diminuição na quantidade de manchas brancas e ausência de espaços remanescentes entre os dentes no final do tratamento (Bishara ${ }^{1}, 1975$; Newman ${ }^{5}, 1965$; Tortamana ${ }^{9}$, 2002).

Em dentes que recebem grande carga mastigatória e que servem de apoio para aparelhos extrabucais, como os $1^{\text {os }}$ e $2^{o s}$ molares, é de bom senso a colocação de bandas. A colagem de acessórios diretamente ao esmalte nesses dentes está sujeita ao risco de descolagens freqüentes, podendo danificar a estrutura do esmalte e prolongar o tempo de tratamento.

Os cimentos de ionômero de vidro (CIV) foram desenvolvidos e divulgados em 1972, por Wilson e Kent ${ }^{10}$. Em virtude da adesão à estrutura dentária e seu potencial de prevenir cáries, esse cimento tem sido o material de escolha dos ortodontistas para cimentaçáo de bandas ortodônticas. Recentemente foi realizada a substituição de parte do ácido CIV convencional por monômeros hidrófilos resultando num material fotoativado ou quimicamente ativado denominado ionômero de vidro modificado por resina, com resistência mecânica imediata à fotoativação e com menor sensibilidade às variaçôes hídricas. Além disso, algumas características da reação ácido/base são mantidas e tornam seu uso fácil inclusive

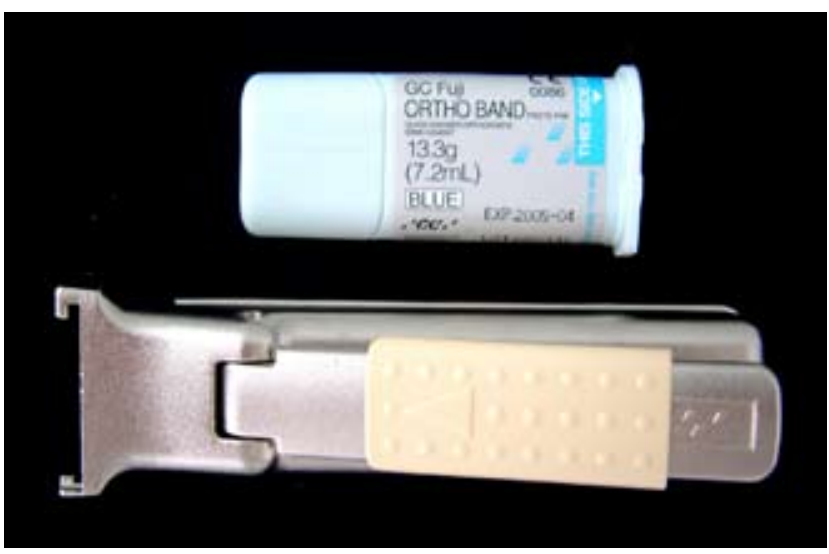

Figura 1 - Cimento de ionômero de vidro Fuji Ortho Band e dispositivo metálico para aplicar o material. em procedimentos preventivos, porém os componentes hidrófilos resultam em contração de polimerização, podendo influenciar na resistência mecânica a longo prazo. (Maccabe $^{2}$, 1998; Mclean ${ }^{3}$, 1994; Mount ${ }^{4}$, 1999; Nichelson ${ }^{6}, 1998$; Smith $\left.{ }^{8}, 1998\right)$.

Freqüentemente novas marcas de ionômero de vidro modificado por resina são desenvolvidas e colocadas à disposição do ortodontista para a cimentação de bandas e colagem de bráquetes. Recentemente, um cimento de ionômero de vidro modificado por resina foi lançado no mercado, denominado Fuji Ortho Band (GC América Corp, Tóquio, Japão), indicado para cimentação de bandas ortodônticas. A evoluçáo desse material baseia-se também na nova forma de apresentação (pasta/pasta), facilitando o proporcionamento e principalmente a manipulação. A reação de geleificação desse material ocorre após a fotoativação por luz e pela reação ácido / base. (Ramali $\left.{ }^{7}, 2005\right)$

O objetivo deste trabalho é mostrar a técnica de cimentação com cimento de ionômero de vidro modificado por resina Fuji Ortho Band, durante os procedimentos de fixação de uma banda ortodôntica no primeiro molar superior esquerdo.

\section{APRESENTAÇÃO COMERCIAL}

O cimento de ionômero de vidro Fuji Ortho Band apresenta-se em embalagem comercial contendo um recipiente com o produto e dispositivo metálico dispensador de material (Figura 1). O Fuji Ortho Band vem acondicionado em duas bisnagas acopladas contendo uma pasta catalisadora (branca) e pasta-base (azul), sendo o diâmetro do compartimento da pasta-base maior do que o da pasta catalisadora, o que proporciona o ma-

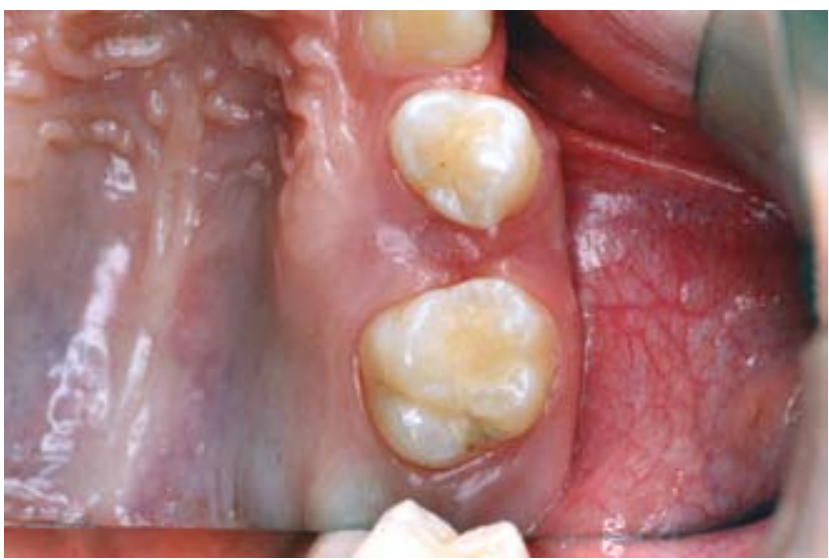

Figura 2 - Dente selecionado para bandagem - $1^{\circ}$ molar superior esquerdo (26). 
Romano FL, Correr Sobrinho L, Correr AB, Ramalli EL, Magnani MBBA, Nouer DF. Cimentação de banda ortodôntica com novo cimento de ionômero de vidro modificado por resina. Revista de Odontologia da Universidade Cidade de São Paulo 2008 jan-abr; 20 (1):87-92

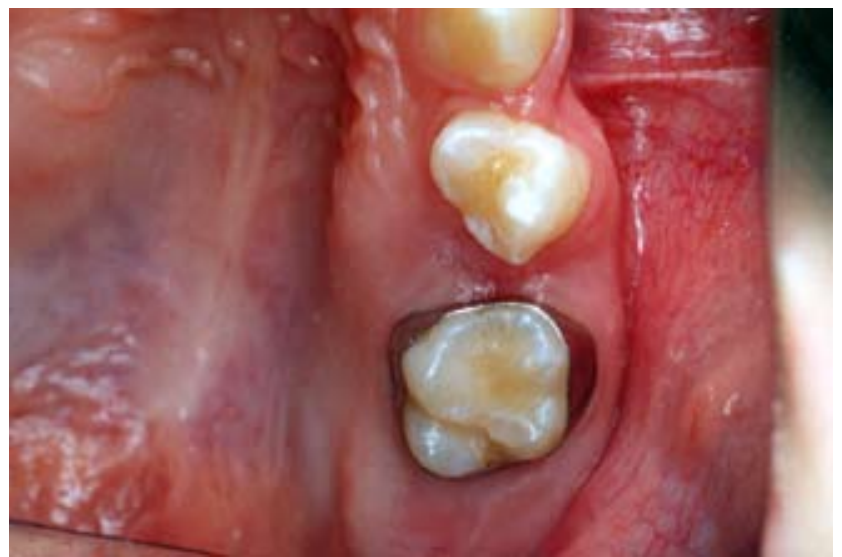

Figura 3 - Adaptação da banda no dente (26).

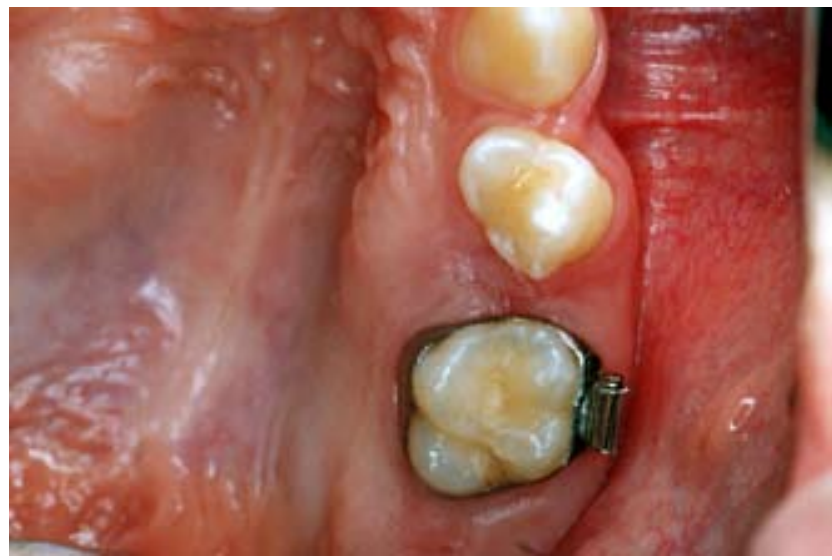

Figura 4 - Banda com acessório ortodôntico soldado na posiçâo correta.

terial volumetricamente.

\section{SEQÜÊNCIA CLÍNICA}

A paciente M. C. D. V. com 10 anos e 11 meses de idade, do sexo feminino, compareceu em consultório particular para tratamento ortodôntico. Após exame clínico inicial e avaliação de documentação ortodôntica, foi constatado que a paciente apresentava maloclusão de Classe II esquelética, com padrão de crescimento equilibrado, relação molar de Classe II-1 ${ }^{\text {a }}$ divisão, subdivisão direita, com overjet e overbite aumentados, dentes 15 e 25 bloqueados por falta de espaço e apinhamento na região ântero-inferior. Foi planejado tratamento ortodôntico corretivo com aparelho fixo na arcada superior e inferior e uso de arco extrabucal apoiado em bandas nos $1{ }^{\text {os }}$ molares superiores. Dessa forma, como passo inicial da montagem do aparelho foram adaptadas bandas nos

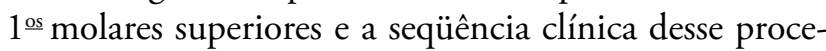
dimento foi demonstrada.
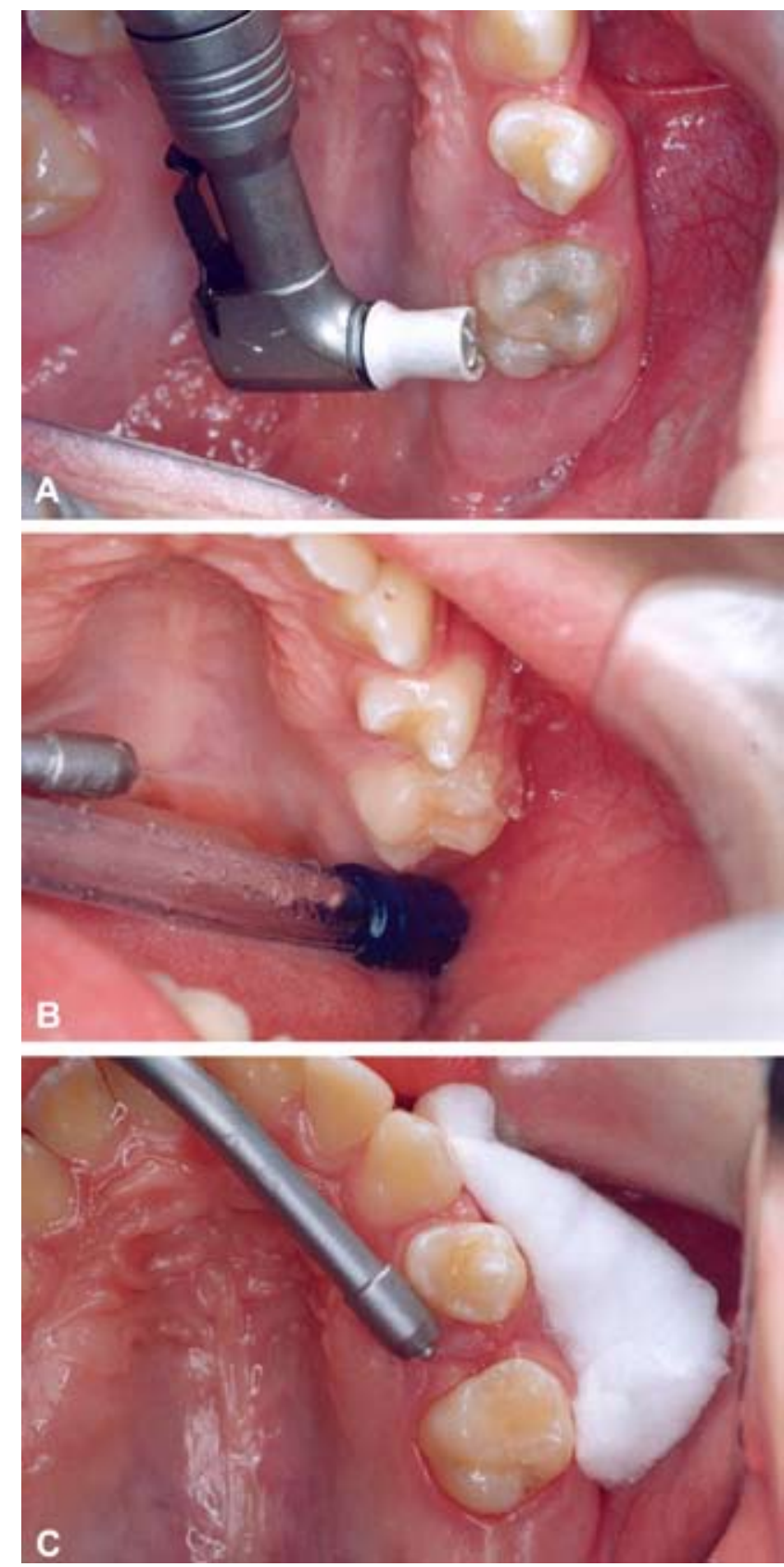

Figura 5 - a, b, c: Profilaxia com pasta de pedra-pomes e água com taça de borracha em motor de baixa rotação, lavagem e secagem com isolamento relativo da área.

Previamente ao procedimento de bandagem, deve-se realizar a separação do dente com elásticos separadores radiopacos de borracha por aproximadamente quatro dias. No presente caso clínico, não foi necessária a separação, pois o $2^{\circ}$ pré-molar superior esquerdo ainda não tinha irrompido, havendo espaço na mesial do $1^{\circ}$ molar para realização da bandagem (Figura 2). Os passos clí- 
Romano FL, Correr Sobrinho L, Correr AB, Ramalli EL, Magnani MBBA, Nouer DF. Cimentação de banda ortodôntica com novo cimento de ionômero de vidro modificado por resina. Revista de Odontologia da Universidade Cidade de São Paulo 2008 jan-abr; 20(1):87-92
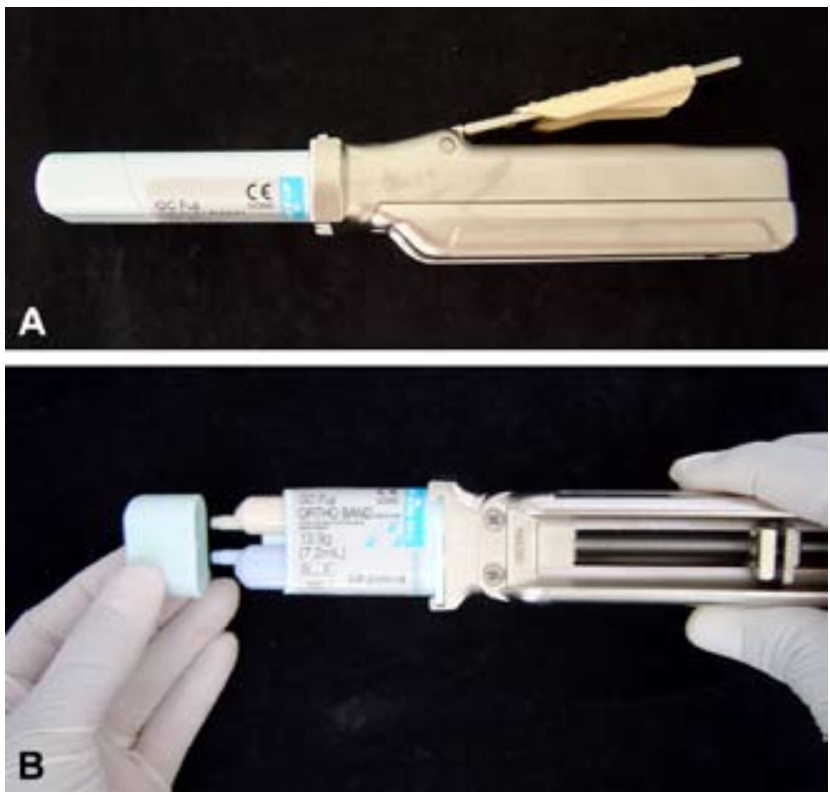

Figura 6 - a, b: Fuji Ortho Band colocado no dispositivo metálico.

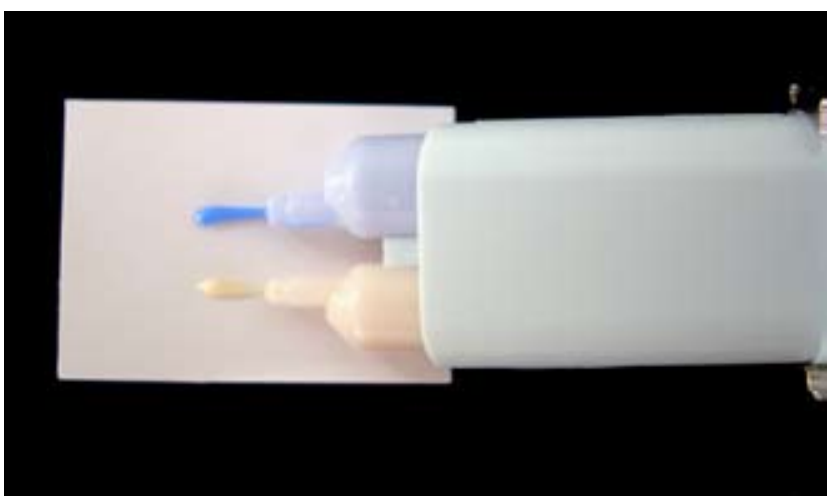

Figura 7 - Material colocado no papel de manipulação.

nicos de confecção e cimentação de banda no dente 26 utilizando o cimento de ionômero de vidro Fuji Ortho Band estão detalhados a seguir.

1 - Seleção da banda e adaptação no dente (Figura 3).

2 - Soldagem parcial do acessório na banda e verificação do posicionamento no sentido mesio-distal e vestíbulo-lingual. Após verificação da posição, realizou-se a soldagem final do acessório na banda (Figura 4).

3 - Profilaxia com pasta de pedra-pomes e água com taça de borracha em toda a coroa do dente, em motor de baixa rotação por aproximadamente 15 segundos, lavagem e secagem pelo mesmo período de tempo. Após profilaxia, realizou-se isolamento relativo da área (Figura $5-a, b, c)$.
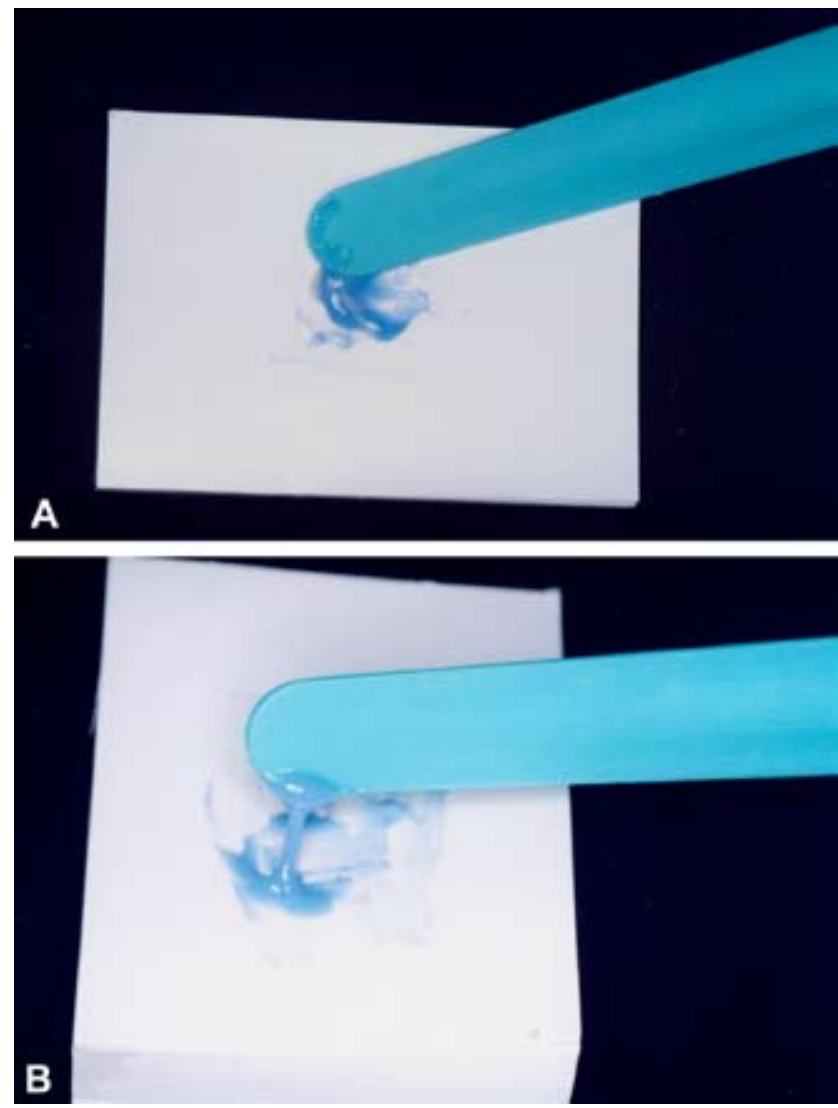

Figura 8 - $a, b$ - Aglutinação do material por aproximadamente 15 segundos.

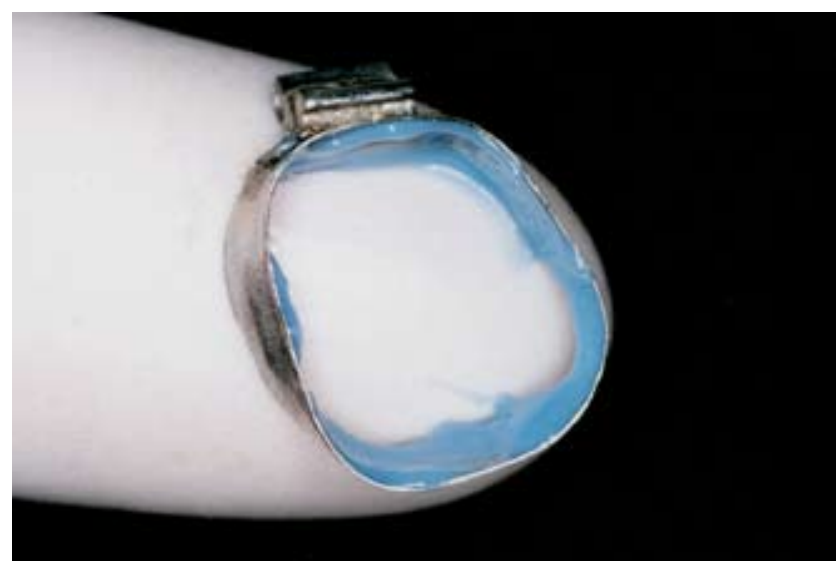

Figura 9 - Cimento de ionômero de vidro Fuji Ortho Band colocado na parte interna da banda.

4 - Manipulação do cimento de ionômero de vidro Fuji Ortho Band de acordo com as recomendaçōes do fabricante. Inicialmente o recipiente contendo as pastas foi colocado no dispositivo metálico (Figura $6-\mathrm{a}, \mathrm{b}$ ), em seguida o êmbolo do dispositivo foi pressionado liberando porções de mesmo comprimento do material, porém 
Romano FL, Correr Sobrinho L, Correr AB, Ramalli EL, Magnani MBBA, Nouer DF. Cimentação de banda ortodôntica com novo cimento de ionômero de vidro modificado por resina. Revista de Odontologia da Universidade Cidade de São Paulo 2008 jan-abr; 20(1):87-92

com espessuras diferentes em papel para manipulação (Figura 7). As duas pastas do cimento foram aglutinadas por aproximadamente 15 segundos, sendo que no final da aglutinação formou-se um filete de $1 \mathrm{~cm}$ de altura (Figura $8-\mathrm{a}, \mathrm{b})$. Após manipulação, o cimento foi colocado em toda a parte interna da banda (Figura 9).

5 - Colocaçáo da banda no dente, pressionando-se em direção cervical, inicialmente com calcador e posteriormente com mordedor de banda até a posição adequada (Figura 10).

6 - Remoção dos excessos com instrumento apropriado tomando-se cuidado de não remover cimento debaixo da banda (Figura 11).

7 - Fotoativaçáo do cimento por 50 segundos, 10 segundos em cada face - oclusal, mesial, distal, vestibular e lingual (Figura 12).

8 - Proteção das margens da banda com esmalte incolor para evitar incorporação de água no ionômero (Fi-

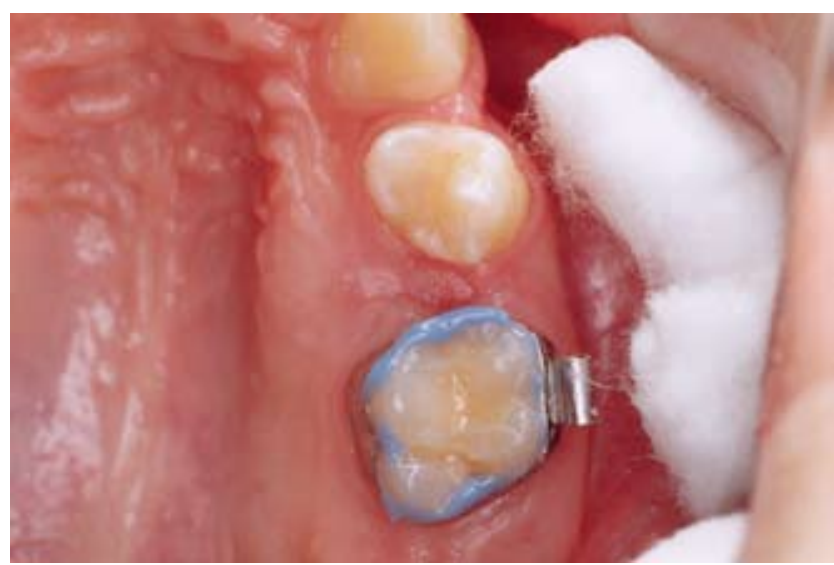

Figura 10 - Colocação da banda no dente: uso de calcador e mordedor com pressáo adequada até posição correta.

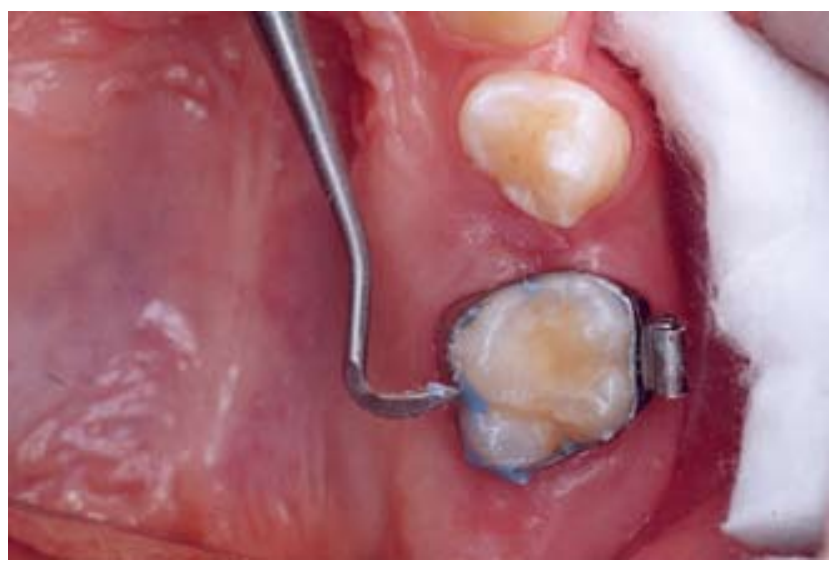

Figura 11 - Remoção dos excessos de material com instrumental adequado. gura 13).

9 - Banda cimentada ao dente (Figura 14).

Nos dentes bandados que serviráo de apoio de aparelhos extrabucais, Placa Lábio-Ativa (PLA), Barra Trans-

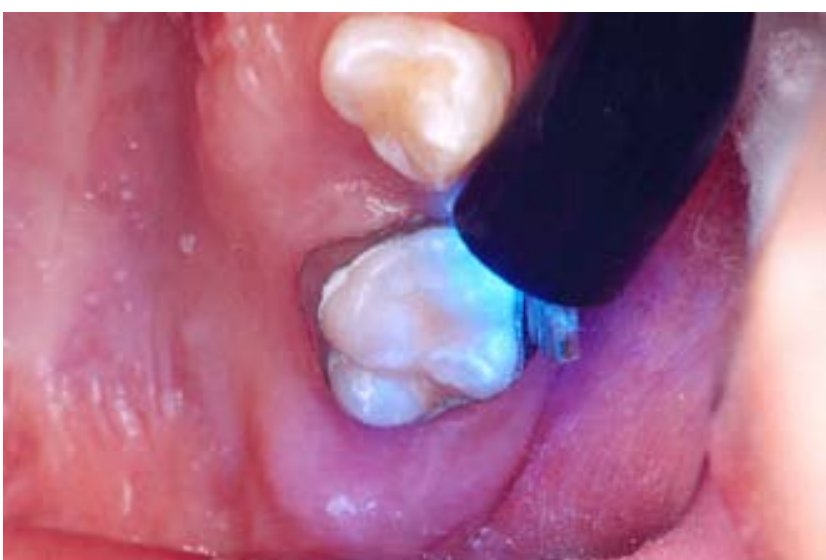

Figura 12 - Fotoativação do cimento após a bandagem, por 50 segundos.

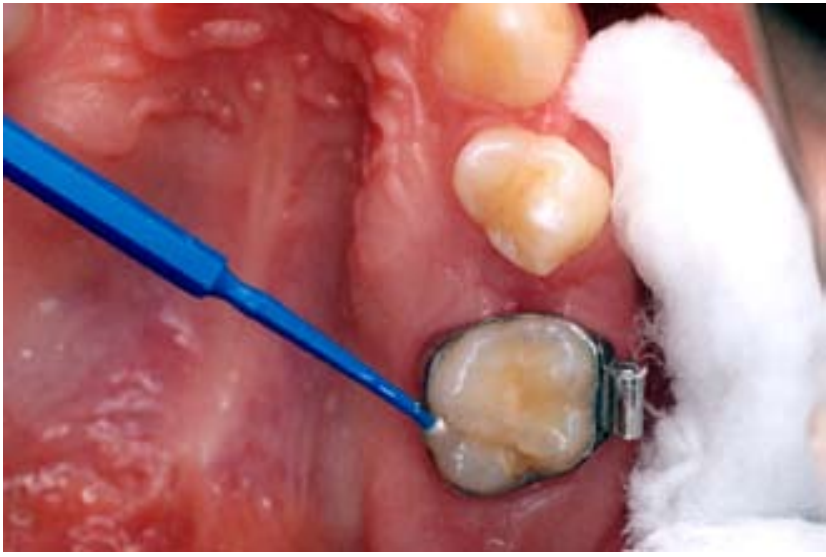

Figura 13 - Selamento das margens da banda com esmalte incolor para proteção do cimento de ionômero de vidro Fuji Ortho Band.

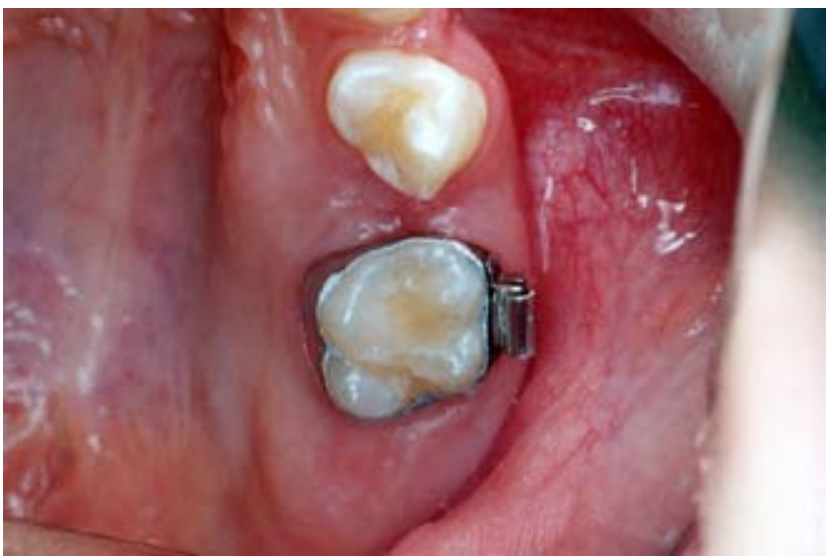

Figura 14 - Aspecto final da banda ortodôntica cimentada. 
Romano FL, Correr Sobrinho L, Correr AB, Ramalli EL, Magnani MBBA, Nouer DF. Cimentação de banda ortodôntica com novo cimento de ionômero de vidro modificado por resina. Revista de Odontologia da Universidade Cidade de São Paulo 2008 jan-abr; 20(1):87-92

palatina, entre outros, é adequado prorrogar a adaptação do aparelho por 24 horas, para evitar descolagem da banda devido à força aplicada pelo dispositivo.

\section{CONSIDERAÇÕES FINAIS}

A cada ano, grande quantidade de novos materiais é colocada à disposição dos ortodontistas, porém, pouco se sabe sobre suas propriedades e eficácia. Neste artigo, um desses materiais, o cimento de ionômero de vidro Fuji Ortho Band, foi apresentado e sua aplicabilidade clínica detalhada. Entretanto, sua biocompatibilidade, estabilidade de cor, eficiência e adesividade ao esmalte ainda não foram comprovadas.

\section{REFERÊNCIAS}

1. Bishara SE, Khowassah MA, Oesterle LJ. Effect of humidity and temperature changes on orthodontic direct-bonding adhesive systems. J Dent Res 1975; 54 (4):751-8.

2. Mccabe JF. Resin-modified glass-ionomers. Biomaterials 1998; 19 (6):521-7.

3. Mclean JW, Nicholson JW, Wilson AD. Proposed Nomenclature For Glass-Ionomer Dental Cements And Related Materials. Quintessence Int 1994; 25 (9):587-9.

4. Mount GJ. Glass Ionomers: a review of their current status. Oper Dent 1999; 24 (2):115-24.

5. Newman G. Epoxy adhesives for orthodontics attachments: progress report. Am J Orthod 1965; 51 (12):901-12.

6. Nicholson JW. Chemistry of glass-ionomer cements: a review. Biomaterials 1998; 19 (6):485- 94.
7. Ramalli EL. Avaliação in vitro da resistência ao cisalhamento de braquetes metálicos com e sem compósito incorporado à base e cimentos de ionômero de vidro com variação da superfície de esmalte. [tese] Piracicaba: Faculdade de Odontologia de Piracicaba - UNICAMP; 2005.

8. Smith DC. Development of glass-ionomer cement systems. Biomaterials 1998; 19 (6):467-78.

9. Tortamano A, Vigorito JW, Nauff F, Garone GM, Santos RSC. Avaliação da resistência à tração de agentes cimentantes para bráquetes ortodônticos. Rev Assoc Paul Cir Dent 2002; 56 (4):259-63.

10. Wilson AD, Kent BE. A new translucent cement for dentistry. Br Dent J 1972; 132 (4):133-5.

Recebido em: 30/01/2007

Aceito em: 12/12/2007 